\title{
Intestinal P-glycoprotein Expression is Multimodally Regulated by Intestinal Ischemia-Reperfusion
}

Yusuke Terada, Jiro Ogura, Takashi Tsujimoto, Kaori Kuwayama, Takahiro Koizumi, Shunichi Sasaki, Hajime Maruyama, Masaki Kobayashi, Hiroaki Yamaguchi, Ken Iseki*

Laboratory of Clinical Pharmaceutics \& Therapeutics, Division of Pharmasciences, Faculty of Pharmaceutical Sciences, Hokkaido University Kita-12-jo, Nishi-6-chome, Kita-ku, Sapporo, Japan

Received, February 17, 2014; Revised, May 29, 2014; Accepted, May 30, 204; Published, June 2, 2014

\begin{abstract}
Purpose. Reactive oxygen species (ROS) have multiple physiological effects that are amount-dependent. ROS are one of the causes of intestinal ischemia-reperfusion (I/R) injury. In this study, we investigated whether the amount of ROS and the degree of intestinal I/R injury affect the expression level of P-glycoprotein (P-gp). Methods. We used hydrogen peroxide $\left(\mathrm{H}_{2} \mathrm{O}_{2}\right)$ as ROS in in vitro experiments. Intestinal $\mathrm{I} / \mathrm{R}$ model rats, which were subjected 15 -min ischemia (I/R-15), were used in in vivo experiments. Results. P-gp expression in Caco-2 cells was increased in response to $1 \mu \mathrm{M}$ of $\mathrm{H}_{2} \mathrm{O}_{2}$ but decreased upon exposure to $10 \mathrm{mM}$ of $\mathrm{H}_{2} \mathrm{O}_{2}$. We previously reported that P-gp expression is decreased after intestinal $\mathrm{I} / \mathrm{R}$ with 30 -min ischemia (I/R-30), which time a large amount of ROS is generated. I/R-15 induced slightly less mucosal and oxidative injury than did I/R-30. P-gp expression in the jejunum was increased at $1 \mathrm{~h}$ after I/R-15, and ileal paracellular permeability was increased. The blood concentration of tacrolimus, a P-gp substrate, was lower during 0-20 min but was higher during 40-90 min post-administration compared with that in the sham-operated rats. P-gp expression in the ileum was decreased at $6 \mathrm{~h}$ after I/R-15, due to abnormal localization of P-gp, resulting in a high blood tacrolimus concentration in rats reperfused for $6 \mathrm{~h}$. Conclusions. ROS multimodally regulate P-gp expression depending on its amount. This is important for understanding the pattern of P-gp expression after intestinal I/R.
\end{abstract}

This article is open to POST-PUBLICATION REVIEW. Registered readers (see "For Readers") may comment by clicking on ABSTRACT on the issue's contents page.

\section{INTRODUCTION}

It is well known that reactive oxygen species (ROS) have multiple physiological effects that are amount-dependent. When the amount of ROS is moderate, ROS act as second intracellular messengers that play roles in the regulation of immunostimulation, cell growth and apoptosis $(1,2)$. On the other hand, When the amount of ROS is excessive, ROS cause cell death by induction of lipid peroxidation and alteration of protein conformation after oxidation of cysteine and methionine residues (3). Intestinal ischemia-reperfusion ( $\mathrm{I} / \mathrm{R})$ occurs in various clinical settings such as small intestinal transplantation, intestinal surgery, circulatory shock, and strangulation ileus. It has been shown that the small intestine is highly sensitive to I/R (4). ROS, which are derived from xanthine oxidase activation, play an important role in acute intestinal I/R injury (5,
6). ROS induce membrane lipid peroxidation followed by loss of intestinal barrier function. Therefore, the degree of intestinal $I / R$ injury can be characterized by the amount of generated ROS.

The small intestine is important for absorption of nutrients and drugs. P-glycoprotein (P-gp), which belongs to the ATP-binding cassette (ABC) superfamily, is expressed on the brush border membrane (BBM) of the small intestine and mediates the efflux of a broad range of endogenous and xenobiotic compounds, including clinical drugs. Several studies have shown that P-gp expression level is altered by intestinal I/R (7-9) and that the bioavailability of P-gp substrates is changed after

Corresponding Author: Ken Iseki, Ph. D., Laboratory of Clinical Pharmaceutics \& Therapeutics, Division of Pharmasciences, Faculty of Pharmaceutical Sciences, Hokkaido University Kita-12-jo, Nishi-6-chome, Kita-ku, Sapporo, Japan; E-mail: ken-i@pharm.hokudai.ac.jp 
intestinal $\mathrm{I} / \mathrm{R}(7,10,11)$. However, results regarding alteration of $\mathrm{P}$-gp expression are not consistent among those studies. We previously reported that the expression level of P-gp was significantly decreased in intestinal $\mathrm{I} / \mathrm{R}$ rats subjected to $30-\mathrm{min}$ ischemia (I/R-30) and 6-h reperfusion (8). Moreover, Tomita et al. (9) reported that P-gp expression was decreased in intestinal $\mathrm{I} / \mathrm{R}$ model rats subjected to 60-min ischemia and 1-h reperfusion. On the other hand, Omae et al. (7) reported that the expression level of $\mathrm{P}$-gp was increased in intestinal $\mathrm{I} / \mathrm{R}$ model rats subjected to I/R-30 and 24-h reperfusion.

Some procedural differences exist among these intestinal $\mathrm{I} / \mathrm{R}$ model rats. We subjected the rats to ischemia by ligating small anastomosing vessels and occluding the superior mesenteric artery (SMA) (8). Omae et al. (7) subjected the rats to ischemia by occluding the SMA without ligating small anastomosing vessels. Tomita et al. (9) subjected the rats to a longer duration of ischemia than the durations in the other studies. Thus, there are differences in the magnitude of $\mathrm{I} / \mathrm{R}$ injury depending on amount of generated ROS among those studies.

In this study, we examined whether the amount of ROS affects the expression of P-gp in Caco-2 cells, which are a model of the human intestinal epithelium. Then we carried out an additional study to investigate $\mathrm{P}$-gp expression in intestinal $\mathrm{I} / \mathrm{R}$ model rats subjected to a short duration of ischemia. We previously reported a decrease in P-gp expression in I/R-30 rats. Since the degree of mucosal injury after intestinal $I / R$ is in proportion to the duration of ischemia (12), we subjected the rats to $15-\mathrm{min}$ ischemia $(\mathrm{I} / \mathrm{R}-15)$ in this study.

\section{MATERIALS AND METHODS}

\section{Chemicals}

Hydrogen peroxide $\left(\mathrm{H}_{2} \mathrm{O}_{2}\right)$ and tacrolimus were purchased from Wako (Osaka, Japan). Fluorescein isothiocyanate-dextran (FD-4) was purchased from Sigma (Tokyo, Japan). All other reagents were of the highest grade available and used without further purification.

\section{Cell culture}

Caco-2 cells obtained from Riken Cell Bank (Tsukuba, Japan) were maintained in plastic culture flasks (Corning Costar Corp., Cambridge, MA). The cell culture conditions were the same as those described previously (13). In the present study, Caco- 2 cells were used between passages 45 and 60 . For $\mathrm{H}_{2} \mathrm{O}_{2}$ addition studies, $\mathrm{H}_{2} \mathrm{O}_{2}$ dissolved in the medium ( $\mathrm{pH}$ 7.4) was added to cells at various concentrations for a period of $6 \mathrm{~h}$.

\section{Animals}

Male Wistar rats, aged 6 weeks, were obtained from Jla (Tokyo, Japan). The rats were housed for at least 1 week (until reaching 190-280 $\mathrm{g}$ in weight). The housing conditions were the same as those described previously (13). The experimental protocols were reviewed and approved by the Hokkaido University Animal Care Committee in accordance with the "Guide for the Care and Use of Laboratory Animals".

\section{Intestinal I/R model}

Surgical procedures were carried out as described in a previous report (8). The animals were anesthetized with sodium pentobarbital (30-40 $\mathrm{mg} / \mathrm{kg}$ body weight, i.p. injection). Through a midline laparotomy, each rat was subjected to $15 \mathrm{~min}$ of ischemia by ligating small anastomosing vessels and occluding the SMA. Reperfusion was induced by removing the clamp. The abdomen was sutured during reperfusion.

\section{Assessment of function of the tight junction}

Function of the tight junction was assessed by mucosal to serosal transport of FD-4. The experiment was performed as described previously (11). Infinite ${ }^{\circledR}$ M200 (Tecan, Kawasaki, Japan) was used to measure FD-4. The permeation rate of FD-4 was expressed as an apparent permeability coefficient $\left(\mathrm{P}_{\text {app }}\right)$ according to the following equation: $\mathrm{P}_{\mathrm{app}}=\mathrm{dQ} / \mathrm{dt} / \mathrm{SC}_{0}$, where $\mathrm{dQ} / \mathrm{dt}$ is the linear appearance rate of mass in the receiver solution, $\mathrm{S}$ is the exposed area $\left(0.64 \mathrm{~cm}^{2}\right)$, and $\mathrm{C}_{0}$ is the initial concentration of FD-4 (100 $\mu \mathrm{g} / \mathrm{mL})$.

\section{Real-time PCR}

Real-time PCR was performed as described previously (8). PCR was performed using rat mdr1a-specific primers through 40 cycles of $94^{\circ} \mathrm{C}$ for $15 \mathrm{~s}, 50^{\circ} \mathrm{C}$ for $30 \mathrm{~s}$ and $72^{\circ} \mathrm{C}$ for $30 \mathrm{~s}$, using rat mdr $1 \mathrm{~b}$-specific primers through 40 cycles of $95^{\circ} \mathrm{C}$ for $15 \mathrm{~s}, 50^{\circ} \mathrm{C}$ for $30 \mathrm{~s}$ and $72^{\circ} \mathrm{C}$ for $30 \mathrm{~s}$ or using human MDR1-specific primers through 40 cycles of $94^{\circ} \mathrm{C}$ for $15 \mathrm{~s}, 58^{\circ} \mathrm{C}$ for $30 \mathrm{~s}$ and $72^{\circ} \mathrm{C}$ for $30 \mathrm{~s}$, in all cases after pre-incubation at $50^{\circ} \mathrm{C}$ for $2 \mathrm{~min}$ and at $95^{\circ} \mathrm{C}$ for 15 min, or using human or rat GAPDH-specific 
primers. The primers specific to hMDR1, hGAPDH, rmdrla, rmdr1b, and rGAPDH were designed on the basis of sequences in GenBank ${ }^{\mathrm{TM}}$ database (accession no.: NM_000927, NM002046, NM_133401, NM_012623, and AF106860, respectively). The sequences of the specific primers were as follows: the sense sequence was 5'-TGC TCA GAC AGG ATG TGA GTT G-3' and the antisense sequence was 5'-AAT TAC AGC AAG CCT GGA ACC-3' for hMDR1, the sense sequence was 5'-AAG GTC ATC CCT GAG CTG AA-3' and the antisense sequence was 5'-TTC TAG ACG GCA GGT CAG GT-3' for hGAPDH, the sense sequence was 5'-GCA GGT TGG CTG GAC AGA TT-3' and the antisense sequence was 5'-GGA GCG CAA TTC CAT GGA TA-3' for rmdr1a, the sense sequence was 5'-CTG CTA TCA TCC ACG GAA CC-3' and the antisense sequence was 5'-GCT GAC GGT CTG TGT ACT GTT G-3' for rmdr1b, and the sense sequence was 5'-ATG GGA AGC TGG TCA TCA AC-3' and the antisense sequence was 5'-GTG GTT CAC ACC CAT CAC AA-3' for rGAPDH. The PCR products were normalized to amplified GAPDH, which was the internal reference gene (housekeeping gene).

\section{Western blot analysis}

Protein extracts from Caco-2 cells and intestinal brush border membrane vesicles (BBMVs) were used for Western blot analysis. The protein extracts from Caco- 2 cells and intestinal BBMVs were prepared by the same methods as those described previously $(8$, 13). Protein concentrations of these samples in clear supernatants were determined by the method of Lowry et al. (14) with bovine serum albumin as a standard. Western blot analysis was performed as described previously (8). A mouse monoclonal antibody to MDR1 (Santa Cruz Biotechnology, Santa cruz, CA) or mouse anti-actin monoclonal antibody (Chemicon, Temecula, CA) (diluted 1:500) was used. Horseradish peroxidase-conjugated goat anti-mouse secondary antibody (Santa Cruz Biotechnology) was used as a secondary antibody. The bands were visualized by enhanced chemiluminescence according to the instructions of the manufacturer (Amersham Biosciences Corp., Piscataway, NJ).

\section{Oxidative injury assessment}

The extent of ROS-induced oxidative damage was assessed indirectly by measuring the level of malondialdehyde (MDA), an intermediate product of lipid peroxidation, as described previously (15). For this study, a PBS suspension of Caco- 2 cells and tissue homogenate were used. Thiobarbituric acid (TBA) solution consisted of $2.6 \mathrm{mM}$ TBA, $918 \mathrm{mM}$ trichloroacetic acid, $0.3 \mathrm{mM} \mathrm{HCl}$, and $1.8 \mathrm{mM}$ 2,6-di-tert-butyl-4-metylphenol in $22 \%$ ethanol. The reaction mixture contained $0.2 \mathrm{~mL}$ of the test sample, $0.2 \mathrm{~mL}$ of $8.1 \%$ SDS, $1.5 \mathrm{~mL}$ of $20 \%$ acetic acid solution ( $\mathrm{pH} 3.5$ ), and $1.5 \mathrm{~mL}$ of TBA solution. The mixture was heated at $95^{\circ} \mathrm{C}$ for $60 \mathrm{~min}$. After cooling with tap water, $2.5 \mathrm{~mL}$ of n-butanol or $1.0 \mathrm{~mL}$ of distilled water and $5.0 \mathrm{~mL}$ of $\mathrm{n}$-butanol were added (Caco-2 cells or tissue homogenate, respectively), and the mixture was shaken vigorously. After centrifugation at $720 \times \mathrm{g}$ for $5 \mathrm{~min}$, the absorbance of the organic layer (upper layer) was measured at 535 $\mathrm{nm}$ with 1,1,3,3-tetraethoxypropane as a standard. The amount of MDA was corrected by protein content.

\section{Pharmacokinetic studies in rats}

Tacrolimus administration was performed by modifications of the method of Yamaguchi et al. (16). Rats were anesthetized with sodium pentobarbital (30-40 $\mathrm{mg} / \mathrm{kg}$ body weight, i.p. injection). The abdominal cavity was opened via a middle incision, and tacrolimus solution $(0.5 \mathrm{mg} / \mathrm{mL})$ was administered via the upper duodenum at $1.0 \mathrm{mg} / \mathrm{kg}$ body weight. The administration volume of tacrolimus solution was $2.0 \mathrm{~mL} / \mathrm{kg}$ body weight. Blood samples (each $0.3 \mathrm{~mL}$ ) were collected into tubes from a jugular vein at $0,5,10,20,40,60$ and $90 \mathrm{~min}$. Tacrolimus concentrations were assayed in whole blood by PRO-Trac ${ }^{\mathrm{TM}}$ II ELISA. PRO-Trac ${ }^{\mathrm{TM}}$ II ELISA was performed according to the manufacturer's protocol. The absorbance was read at $450 \mathrm{~nm}$ by an absorption spectrometer (Infinite ${ }^{\circledR}$ M200, TECAN JAPAN). The area under the concentration-time curve (AUC) of tacrolimus was calculated using the trapezoidal rule from the concentration-time curve. The maximum drug concentration $\left(\mathrm{C}_{\max }\right)$ and the maximum drug concentration time $\left(\mathrm{T}_{\max }\right)$ were calculated by Origin $\mathrm{J}$. Total clearance (CL) was calculated by the following equation: $\mathrm{CL}=\mathrm{D} / \mathrm{AUC}$, where $\mathrm{D}$ is the dosage amount.

\section{STATISTICAL ANALYSIS}

Statistical significance was evaluated using Dunnett's 
test (in vitro experiments) or Student's $t$-test (in vivo experiments). A value of $\mathrm{p}<0.05$ was considered significant.

\section{RESULTS}

\section{MDA level in $\mathrm{H}_{2} \mathrm{O}_{2}$-treated Caco-2 cells}

To investigate the effect of $\mathrm{H}_{2} \mathrm{O}_{2}$, one of the ROS, on the extent of oxidative injury, Caco- 2 cells were exposed to $\mathrm{H}_{2} \mathrm{O}_{2}$ for $6 \mathrm{~h}$. The level of MDA, a reliable marker for lipid peroxidation, was increased in a concentration-dependent manner (Fig. 1).

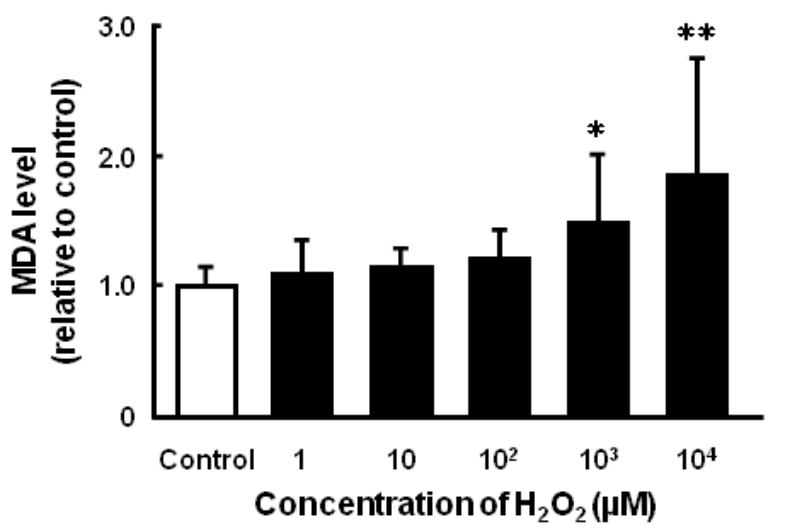

Figure 1. Effect of hydrogen peroxide on lipid peroxide in Caco-2 cells. Caco-2 cells were exposed to hydrogen peroxide for $6 \mathrm{~h}$. Control was incubated in the medium for $6 \mathrm{~h}$. Each column represents the mean with S.D. of 9-18 measurements. $* \mathrm{P}<0.05$ significantly different from the control. $* * \mathrm{P}<0.01$.

\section{P-gp expression in $\mathrm{H}_{2} \mathrm{O}_{2}$-treated Caco-2 cells}

Next, to clarify the effect of $\mathrm{H}_{2} \mathrm{O}_{2}$ concentration on P-gp expression level, we examined the change in mRNA level of MDR1, which encodes P-gp, in Caco-2 cells. The mRNA level of MDR1 was increased in response to $1 \mu \mathrm{M} \mathrm{H}_{2} \mathrm{O}_{2}$ but was decreased in response to more than $1 \mu \mathrm{M} \mathrm{H}_{2} \mathrm{O}_{2}$ in a concentration-dependent manner (Fig. 2A). The mRNA level of MDR1 was significantly decreased upon exposure to $10 \mathrm{mM} \mathrm{H} \mathrm{H}_{2}$ compared with that in control cells (Fig. 2A). Moreover, P-gp protein expression was increased in response to $1 \mu \mathrm{M} \mathrm{H}_{2} \mathrm{O}_{2}$ but decreased in response to more than $1 \mu \mathrm{M} \mathrm{H}_{2} \mathrm{O}_{2}$ in a concentration-dependent manner (Fig. 2B). This result was associated with the level of MDR1 mRNA.

\section{MDA levels in intestinal $\mathrm{I} / \mathrm{R}-15$ rats}

Since the degree of $I / R$ injury is increased with prolongation of the duration of ischemia to more than $15 \mathrm{~min}$ in rats (12), we used intestinal I/R-15 rats to induce slight intestinal $\mathrm{I} / \mathrm{R}$ injury compared to intestinal I/R-30 rats in this study. Firstly, to confirm that intestinal $\mathrm{I} / \mathrm{R}$ injury is induced even by intestinal I/R-15, we evaluated the occurrence of oxidative injury after intestinal I/R-15 by measuring the levels of MDA. The MDA levels in the jejunum and ileum were increased at $1 \mathrm{~h}$ after intestinal I/R-15 compared to those in sham-operated rats (Fig. 3A and 3B). These results indicated that oxidative injury in the intestine was induced by intestinal I/R-15.

\section{Intestinal paracellular permeability in intestinal I/R-15 rats}

Intestinal $\mathrm{I} / \mathrm{R}$ is well known to affect intestinal paracellular permeability (17). Although $\mathrm{P}_{\text {app }} \mathrm{s}$ of FD-4 through jejunal membranes of intestinal I/R-15 rats reperfused for $1 \mathrm{~h}$ and $6 \mathrm{~h}$ were not altered, $\mathrm{P}_{\mathrm{app}}$ of FD-4 through jejunal membranes of intestinal I/R-15 rats reperfused for $24 \mathrm{~h}$ was significantly decreased (Fig. 4A). On the other hand, $\mathrm{P}_{\mathrm{app}} \mathrm{S}$ of FD-4 through ileal membranes of intestinal $\mathrm{I} / \mathrm{R}-15$ rats reperfused for $1 \mathrm{~h}$ and $6 \mathrm{~h}$ were significantly higher than those in sham-operated rats (Fig. 4B).

\section{(A) MDR1 level}

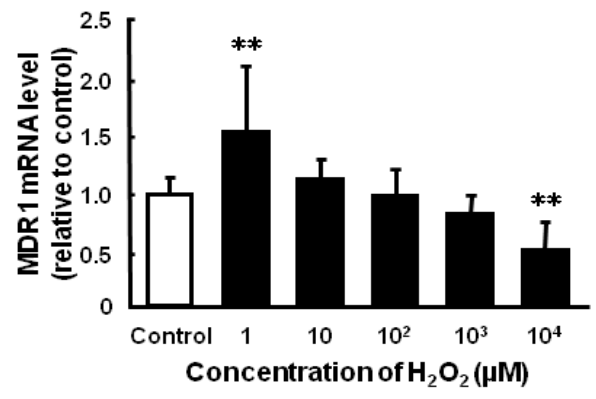

(B) P-gp expression

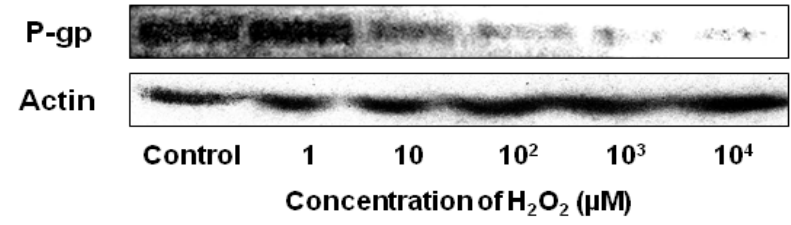

Figure 2. Effects of hydrogen peroxide on MDR1 level (A) and P-gp expression level (B) in Caco-2 cells. Caco-2 cells were exposed to hydrogen peroxide for $6 \mathrm{~h}$. Control was incubated in the medium for $6 \mathrm{~h}$. Each column represents the mean with S.D. of 5-8 measurements. $* * \mathrm{P}<0.01$ significantly different from the control. Western blot data shown are typical results from three independent experiments. 
$\mathrm{P}_{\text {app }}$ of FD-4 through ileal membranes of intestinal I/R-15 rats reperfused for $24 \mathrm{~h}$ was almost the same as that in sham-operated rats (Fig. 4B).

\section{P-gp expression in intestinal $\mathrm{I} / \mathrm{R}-15$ rats}

We examined mRNA levels of mdrla and mdrlb, which encode P-gp, and P-gp expression levels in the jejunum and ileum after intestinal I/R-15. In the jejunum, as shown in Fig. 5, the mRNA levels of mdrla and mdrlb were increased at $1 \mathrm{~h}$ after intestinal I/R-15. The mdrlb mRNA level was also increased at $6 \mathrm{~h}$ after intestinal I/R-15 (Fig. 5B). On the other hand, the mdrla mRNA level was decreased at $24 \mathrm{~h}$ after intestinal I/R-15 (Fig. 5A). The expression level of P-gp in the jejunal BBM was increased at $1 \mathrm{~h}$ but was not significantly altered at 6 or $24 \mathrm{~h}$ after intestinal I/R-15 (1.8-fold at $1 \mathrm{~h}$, 0.81 -fold at $6 \mathrm{~h}$ and 1.0 -fold at $24 \mathrm{~h}$ ) (Fig. 5C). In the ileum, mdrla and mdrlb mRNA levels were not altered at any time after intestinal I/R-15 (Fig. 6A and $6 \mathrm{~B})$. On the other hand, the expression level of P-gp in the ileal BBM was 0.62-fold decreased at $6 \mathrm{~h}$ after intestinal I/R (Fig. 6C) but was not altered in the ileal homogenate at any time $(0.96$-fold at $1 \mathrm{~h}, 1.1$-fold at $6 \mathrm{~h}$ and 1.0 -fold at $24 \mathrm{~h}$ ) (data not shown).

\section{Pharmacokinetics of tacrolimus in intestinal I/R-15 rats}

Finally, we investigated whether the pharmacokinetics of tacrolimus is affected by intestinal I/R. Fig. 7 shows the time courses of blood tacrolimus concentration after intraintestinal administration at a dose of $10 \mathrm{mg} / \mathrm{kg}$. The blood tacrolimus concentration in intestinal $\mathrm{I} / \mathrm{R}-15$ rats reperfused for $1 \mathrm{~h}$ was lower during 0-20 min but higher during 40-90 min compared with that in sham-operated rats (Fig. 7A). $\mathrm{T}_{\max }$ in intestinal $\mathrm{I} / \mathrm{R}-15$ rats reperfused for $1 \mathrm{~h}$ was higher than that in sham-operated rats, but $\mathrm{AUC}_{0-90}$ in intestinal $\mathrm{I} / \mathrm{R}$ rats reperfused for $1 \mathrm{~h}$ was almost the same as that in sham-operated rats (Table 1). The blood tacrolimus concentration in intestinal I/R-15 rats reperfused for 6 $\mathrm{h}$ was higher than that in sham-operated rats (Fig. 7B). AUC $_{0-90}, T_{\max }$ and $\mathrm{C}_{\max }$ in intestinal $\mathrm{I} / \mathrm{R}-15$ rats reperfused for $6 \mathrm{~h}$ were 1.6-fold, 1.4-fold and 1.5-fold higher than those in sham-operated rats, respectively, but $\mathrm{AUC}_{0-90}$ and $\mathrm{C}_{\max }$ were not significantly different (Table 2). The blood tacrolimus concentration in intestinal I/R-15 rats reperfused for $24 \mathrm{~h}$ was almost the same as that in sham-operated rats (Fig. 7C). Pharmacokinetic parameters in intestinal $\mathrm{I} / \mathrm{R}-15$ rats reperfused for $24 \mathrm{~h}$ were also the same as those in sham-operated rats (Table 2).

\section{DISCUSSION}

One of the mechanisms of intestinal $I / R$ injury is thought to be excessive production of ROS. ROS have multiple physiological effects that are amount-dependent (18). Moderate amount of ROS acts as an intracellular signaling molecules that are indispensable to the living body. In contrast, excessive amount of ROS induce severe oxidative organ injury. We focused on this bilateral character of ROS and investigated the effect of the amount of ROS on P-gp expression.
(A) Jejunum

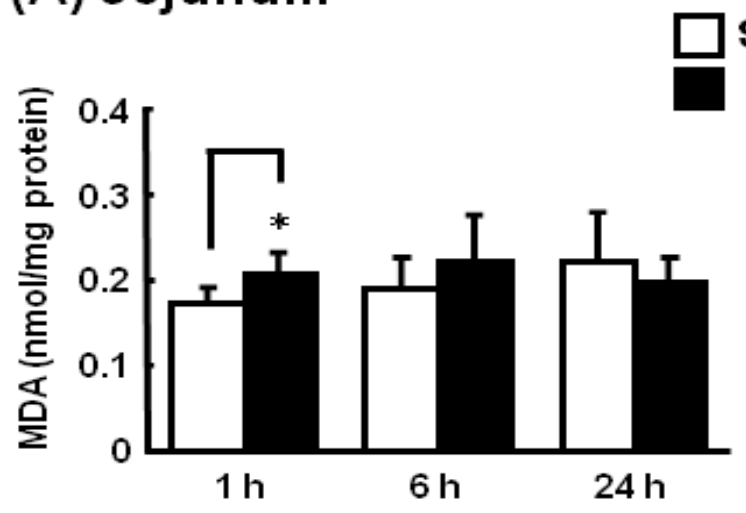

Sham I/R

\section{(B) Ileum}

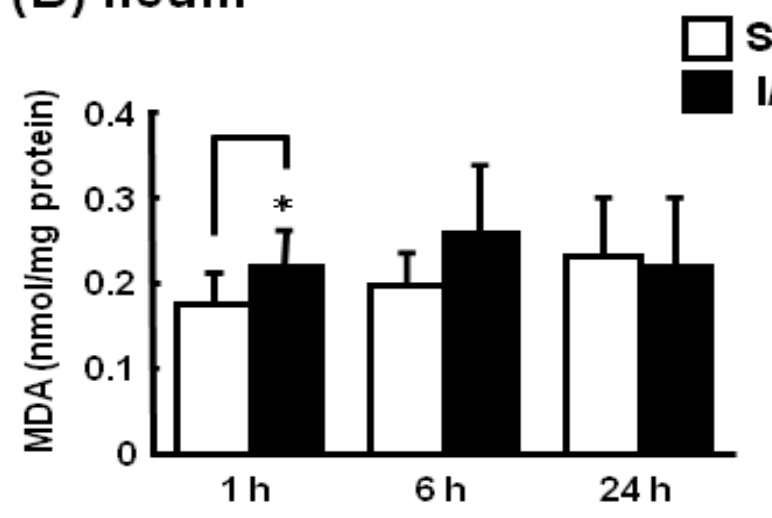

Figure 3. Time courses of MDA levels in the jejunum (A) and ileum (B) after intestinal I/R-15. Each column represents the mean with S.D. of 3-7 measurements. *; $\mathrm{P}<0.05$ significantly different from sham. 
(A) Jejunum

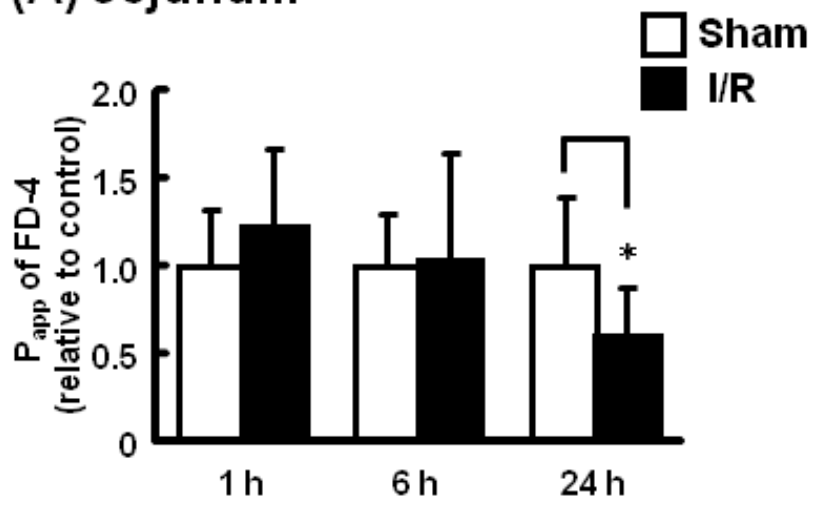

(B) Ileum

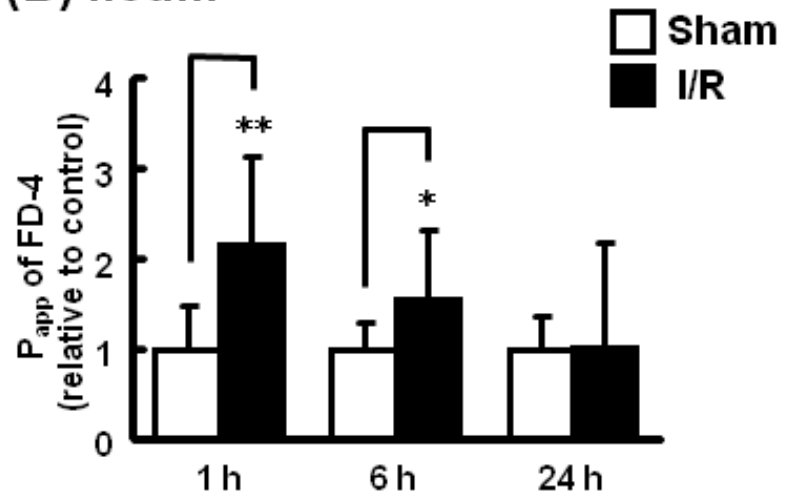

Figure 4. Time courses of $\mathrm{P}_{\text {app }}$ of FD-4 through jejunal (A) and ileal (B) membranes of intestinal I/R-15 rats. Each column represents the mean with S.D. of 11-15 measurements ( $\mathrm{n}=4-5)$. *; $\mathrm{P}<0.05$ significantly different from sham. ** $<0.01$.

(A) mdr1a level

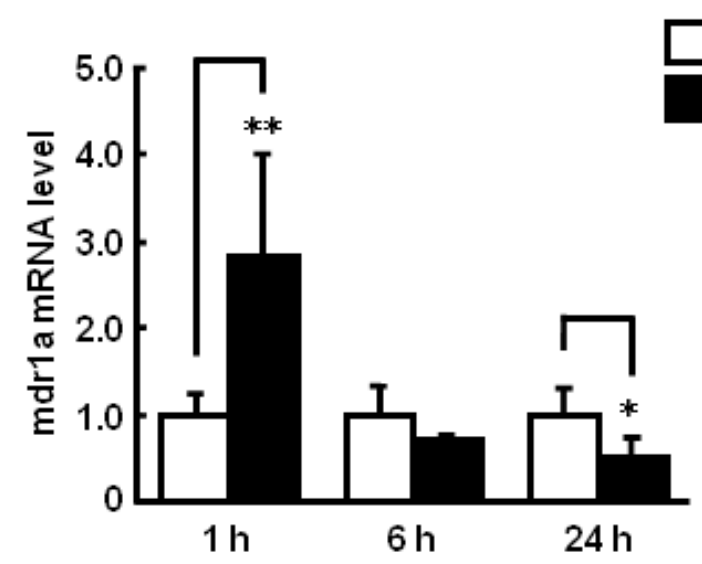

(B) mdr1b level

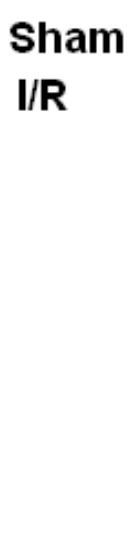

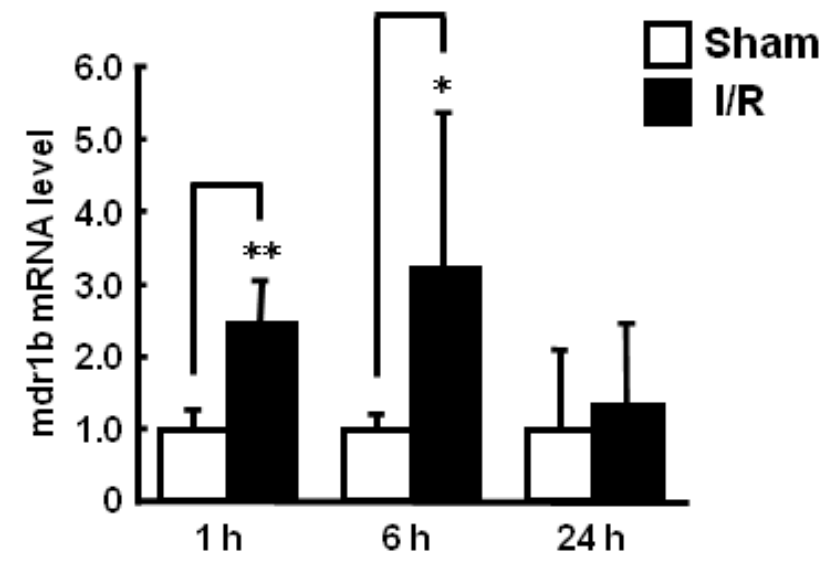

(C) P-gp expression

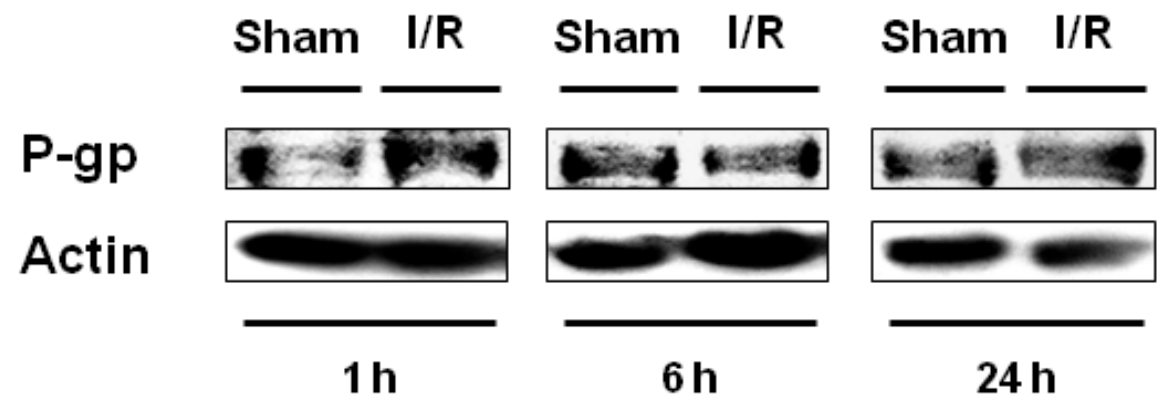

Figure 5. Time courses of mdrla (A), mdrlb (B) and P-gp (C) levels in the jejunum after intestinal I/R-15. Each column represents the mean with S.D. of 4-6 measurements. ${ }^{*} \mathrm{P}<0.05$ significantly different from sham. ${ }^{* *} \mathrm{P}<0.01$. Western blotting using jejunal BBMVs at 1,6 and $24 \mathrm{~h}$ after $\mathrm{I} / \mathrm{R}-15$. Western blot data shown are typical results from three independent experiments. 


\section{(A) mdr1a level}

\section{(B) mdr1b level}

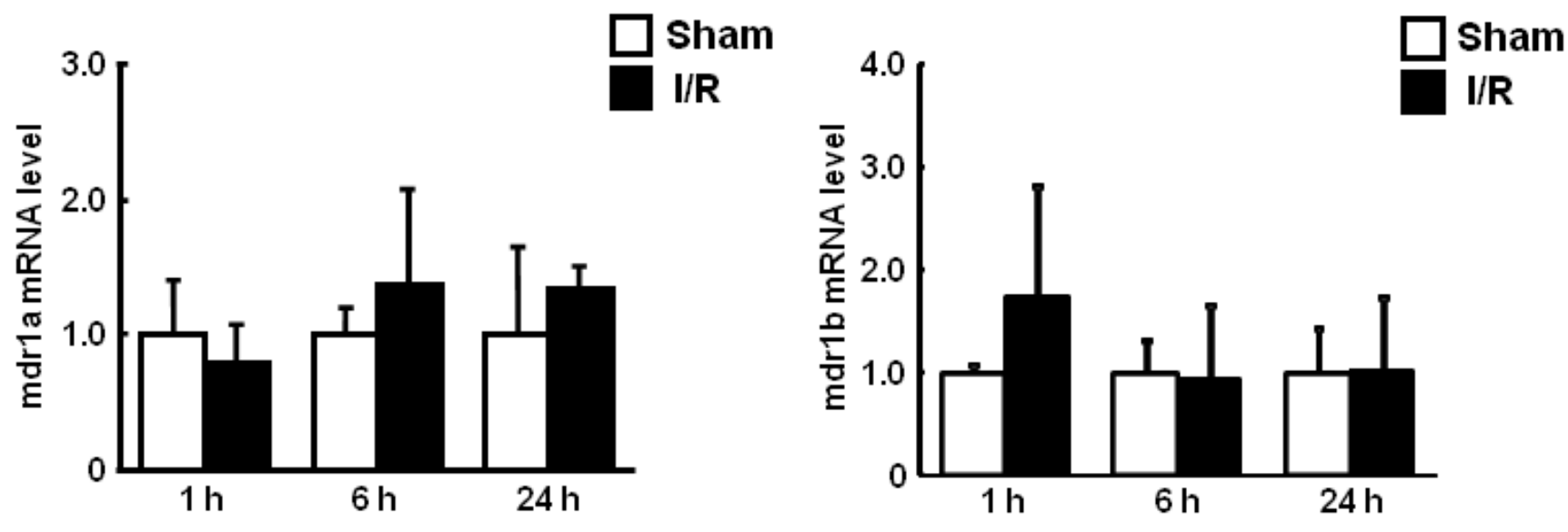

\section{(C) P-gp expression}

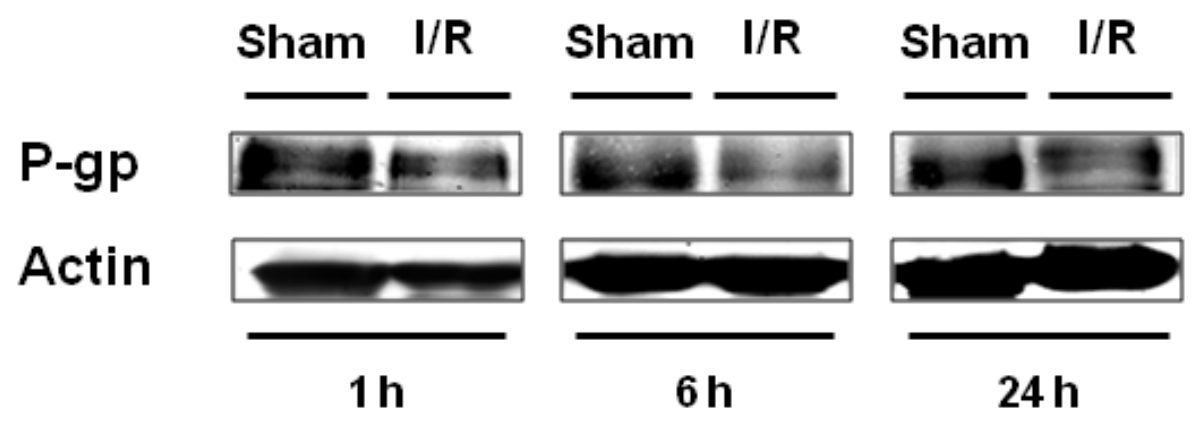

Figure 6. Time courses of mdrla (A), mdr1b (B) and P-gp (C) levels in the ileum after intestinal I/R-15. Each column represents the mean with S.D. of 4-6 measurements. Western blotting using ileal BBMVs at 1, 6 and $24 \mathrm{~h}$ after I/R-15. Western blot data shown are typical results from three independent experiments.

Firstly, we assessed the effects of various amounts of ROS on P-gp expression in Caco-2 cells, which are widely used as an intestinal model. P-gp expression in Caco-2 cells was increased in response to $1 \mu \mathrm{M}$ of $\mathrm{H}_{2} \mathrm{O}_{2}$ but was decreased upon exposure to $10 \mathrm{mM}$ $\mathrm{H}_{2} \mathrm{O}_{2}$. Moreover, the MDR1 mRNA level with $1 \mu \mathrm{M}$ to $10 \mathrm{mM} \mathrm{H} \mathrm{O}_{2}$ showed a negative correlation with the extent of oxidative stress evaluated by measuring MDA level ( $\mathrm{r}:-0.900, \mathrm{p}<0.05)$. We therefore concluded that P-gp expression is increased by a small amount of ROS but is decreased by a large amount of ROS, which is accordance with the results of a previous study of Nagira et al. using tertiary-butylhydroperoxide (19). In our previous study, we revealed that I/R-30 caused severe damage of the intestinal mucosa and that mdrla mRNA level was decreased at $6 \mathrm{~h}$ after I/R-30 in the ileum, resulting in a decrease in P-gp expression level (8). MDA level was increased by 2.1 fold in intestinal $\mathrm{I} / \mathrm{R}-30$ rats (15) and was increased by 1.9 fold in Caco-2 cells exposed to $10 \mathrm{mM} \mathrm{H}_{2} \mathrm{O}_{2}$ (Fig. 1). These findings indicated that the small intestine after I/R-30 was affected by severe oxidative stress that was similar to or greater than that induced in Caco-2 cells exposed to $10 \mathrm{mM} \mathrm{H}_{2} \mathrm{O}_{2}$. Boros et al. (12) reported that mucosal injury level after intestinal $I / R$ is significantly increased with prolongation of the duration of ischemia in rats to more than $15 \mathrm{~min}$. $\mathrm{I} / \mathrm{R}-15$ rats have been used to assess diverse phenomena caused by slight $\mathrm{I} / \mathrm{R}$ injury (20), and $\mathrm{I} / \mathrm{R}-30$, but not $\mathrm{I} / \mathrm{R}-15$, has been shown to induce epithelial destruction and DNA fragmentation (21). 

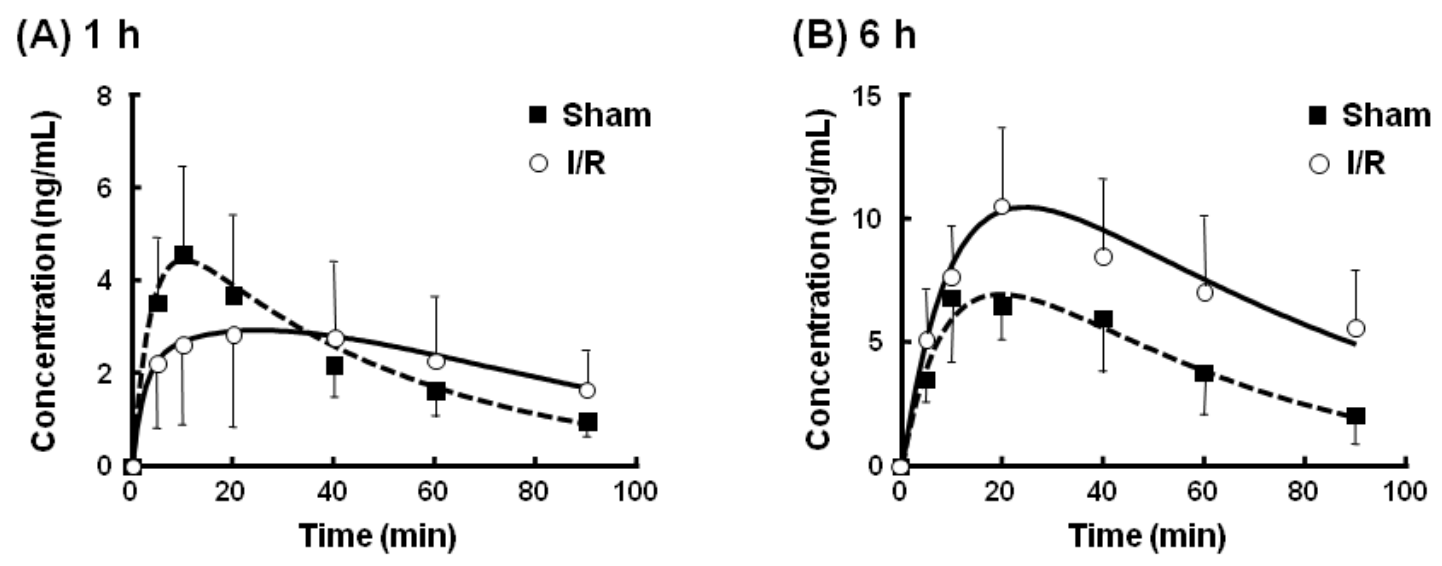

(C) $24 \mathrm{~h}$

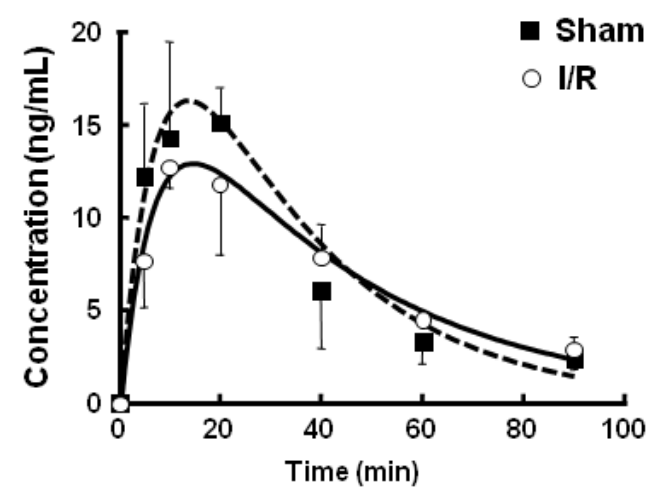

Figure 7. Blood concentration of tacrolimus after intraintestinal administration in intestinal $\mathrm{I} / \mathrm{R}-15$ rats. The reperfusion times were $1 \mathrm{~h} \mathrm{(A),} 6 \mathrm{~h}$ (B) and $24 \mathrm{~h}(\mathrm{C})$. Each point represents the mean \pm S.D. of 3-6 measurements.

Table 1. Pharmacokinetic parameters of tacrolimus after intestinal I/R

\begin{tabular}{ccclc}
\hline & & $\begin{array}{c}\mathrm{AUC}_{0-90} \\
((\mathrm{ng} / \mathrm{mL}) \cdot \mathrm{min})\end{array}$ & \multicolumn{1}{c}{$\begin{array}{c}\mathrm{T}_{\max } \\
(\mathrm{min})\end{array}$} & $\begin{array}{c}\mathrm{C}_{\max } \\
(\mathrm{ng} / \mathrm{mL})\end{array}$ \\
\hline \multirow{2}{*}{$1 \mathrm{~h}$} & Sham & $206 \pm 71$ & $11.1 \pm 4.0$ & $4.6 \pm 1.8$ \\
& I/R & $213 \pm 128$ & $26.8 \pm 10.1^{*}$ & $3.2 \pm 1.8$ \\
\multirow{2}{*}{$6 \mathrm{~h}$} & Sham & $413 \pm 145$ & $19.1 \pm 1.6$ & $7.1 \pm 2.2$ \\
& I/R & $676 \pm 237$ & $25.8 \pm 1.4^{* *}$ & $10.9 \pm 3.0$ \\
\multirow{2}{*}{$24 \mathrm{~h}$} & Sham & $639 \pm 162$ & $13.9 \pm 4.3$ & $17.0 \pm 1.9$ \\
& I/R & $632 \pm 71$ & $13.6 \pm 3.2$ & $13.7 \pm 2.7$ \\
\hline
\end{tabular}

Each value represents the mean \pm S.D. of 3-5 measurements. *; $P<0.05$ significantly different from sham. ${ }^{* *}: P<0.01$.

Based on those reports, we decided to make the duration of ischemia shorter than $30 \mathrm{~min}$ and we used $\mathrm{I} / \mathrm{R}-15$ rats in this study to investigate the effects of slight $\mathrm{I} / \mathrm{R}$ injury on expression of P-gp in the small intestine. Maximum MDA levels in the jejunum and ileum in intestinal I/R-15 rats (Fig. 4) were lower 
than those in intestinal $\mathrm{I} / \mathrm{R}-30$ rats (15). These findings suggest that shortening the duration of ischemia attenuates the oxidative injury in the small intestine after $\mathrm{I} / \mathrm{R}$, which is accordance with several reports $(12,20,21)$. In intestinal $\mathrm{I} / \mathrm{R}-15$ rats, mdr1a (Fig. 5A) and mdrlb (Fig. 5B) mRNA levels in the jejunum were increased at $1 \mathrm{~h}$ after intestinal $\mathrm{I} / \mathrm{R}$, resulting in an increase in P-gp expression level (Fig. 5C). This significant up-regulation of P-gp expression was not observed in intestinal I/R-30 rats (8). These results suggest that ROS have a bilateral effect on P-gp expression in a living body, being consistent with the results of in vitro experiments (Fig. 2). Several studies have shown that P-gp expression level is altered by intestinal $\mathrm{I} / \mathrm{R}$, but results regarding alteration of $\mathrm{P}$-gp expression are not consistent among those studies (7-9). Some procedural differences exist among these intestinal $\mathrm{I} / \mathrm{R}$ model rats, such as ischemia duration, grade of ischemia and reperfusion time, which have been shown to affect the extent of intestinal I/R injury ( 9 , $12,22)$. Thus, there were differences in the amount of generated ROS after intestinal $\mathrm{I} / \mathrm{R}$ among those studies, resulting in the difference in the alteration of $\mathrm{P}$-gp expression. In the ileum, P-gp expression in the ileal BBM was decreased at $6 \mathrm{~h}$ after intestinal I/R-15 (Fig. 6C), though mdrla and mdrlb mRNA levels (Figs. 6A and 6B) and $\mathrm{P}$-gp protein expression in the ileal homogenate (data not shown) were not decreased. Takizawa et al. (23) reported abnormal localization of P-gp in the ileal membrane during intestinal $\mathrm{I} / \mathrm{R}$. This finding suggests that abnormal localization of P-gp also occurs in our intestinal I/R-15 model rats.

P-gp expression level in the intestine is an important pharmacokinetic factor for the immunosuppressant tacrolimus in small intestinal transplantation (24). Blood concentration of tacrolimus in intestinal I/R-15 rats reperfused for $1 \mathrm{~h}$ was lower during 0-20 min post-administration but higher during 40-60 min post-administration compared with that in sham-operated rats. Simomura et al. (25) reported that the site of absorption of tacrolimus was the whole ileum in jejunum-resected rats, resulting in $T_{\max }$ of tacrolimus being significantly higher than that in sham-operated rats. Considering this finding, the increase in jejunal P-gp expression level in intestinal I/R-15 rats causes the lower blood tacrolimus concentration in the period from 0 to $20 \mathrm{~min}$ post-administration, resulting in $\mathrm{T}_{\max }$ of tacrolimus being significantly higher than that in sham-operated rats. The paracellular pathway to the lateral intercellular space via tight junctions between epithelial cells is another transport pathway that can function as a drug absorption route $(26,27)$.
Ileal paracellular permeability was 2.2-fold increased at $1 \mathrm{~h}$ after intestinal I/R-15 (Fig. 4B), resulting in an increase in absorption of tacrolimus from the ileum. The increase in ileal paracellular permeability in intestinal I/R-15 rats reperfused for $1 \mathrm{~h}$ might cause the higher blood tacrolimus concentration in the period from 40 to $90 \mathrm{~min}$ post-administration. In I/R-15 rats reperfused for $6 \mathrm{~h}$, blood tacrolimus concentration was higher than that in sham-operated rats (Fig. 7). The high blood tacrolimus concentration in intestinal $\mathrm{I} / \mathrm{R}-15$ rats could be explained by the induction of absorption of tacrolimus resulting from the decrease in P-gp expression (Fig. 6) and the increase in paracellular permeability (Fig. 4B) in the ileum. In intestinal I/R-30 rats, P-gp expression in the ileum was also decreased at $6 \mathrm{~h}(8)$. The tacrolimus concentration in intestinal I/R-30 rats reperfused for 6 $\mathrm{h}$ was higher than that in sham-operated rats (data not shown). $\mathrm{AUC}_{0-90}, \mathrm{~T}_{\max }$ and $\mathrm{C}_{\max }$ in intestinal $\mathrm{I} / \mathrm{R}-30$ rats reperfused for $6 \mathrm{~h}$ were 2.2-fold, 1.7-fold and 1.7-fold higher than those in sham-operated rats, respectively. However, the mechanisms of the decrease in $\mathrm{P}$-gp expression were different in intestinal $\mathrm{I} / \mathrm{R}-15$ rats and intestinal $\mathrm{I} / \mathrm{R}-30$ rats. The decrease in P-gp expression in intestinal $\mathrm{I} / \mathrm{R}-15$ rats might be caused by abnormal localization of P-gp, but that in intestinal I/R-30 rats was caused by the decrease in mdrla mRNA level. The mechanism of this abnormal localization of P-gp in intestinal I/R-15 rats is not clear. Further detailed investigation is needed to elucidate this regulation of $\mathrm{P}$-gp in intestinal I/R-15 rats. Jenunal paracellular permeability was significantly decreased at $24 \mathrm{~h}$ after intestinal I/R-15. We currently have little information to explain the phenomenon. It is known that the protein expression levels of claudin-1 and -4, which play a crucial role in the barrier function of tight junctions, is significantly increased at $24 \mathrm{~h}$ after intestinal I/R (28). This finding suggests that the increase in claudin-1 and -4 expression might cause the decrease in jejunal paracellular permeability at 24 after intestinal $\mathrm{I} / \mathrm{R}$. In sham-operated rats, $\mathrm{AUC}_{0-90}$ and $\mathrm{C}_{\max }$ were increased with experimental time. We did not investigate the factors leading to the alterations of $\mathrm{AUC}_{0-90}$ and $\mathrm{C}_{\max }$ by the sham operation, but it is possible that laparotomy may have contributed to these alterations. Indeed, several workers reported that laparotomy induced the production of stress hormones $(29,30)$.

Intestinal ischemia remains a serious complication of intestinal surgery including small intestinal transplantation. Tacrolimus is a key drug used in organ transplantation. Tacrolimus shows large intra- and inter-individual pharmacokinetic variability, 
and that increases the risk of rejection and graft loss (31). Thus, modifying the dosage of tacrolimus is necessary for transplant recipients to secure better postoperative control. The present findings provide useful information for immunosuppressive therapy with tacrolimus.

In conclusion, we clarified that P-gp expression in Caco-2 cells was increased in response to $1 \mu \mathrm{M}$ of $\mathrm{H}_{2} \mathrm{O}_{2}$ but decreased upon exposure to $10 \mathrm{mM}$ of $\mathrm{H}_{2} \mathrm{O}_{2}$. Moreover, P-gp expression in the jejunum was increased at $1 \mathrm{~h}$ after intestinal I/R-15, when slight oxidative injury is occurring, resulting in reduction of the absorption rate of tacrolimus. In the ileum, P-gp expression in the BBM was decreased at $6 \mathrm{~h}$ after intestinal $\mathrm{I} / \mathrm{R}-15$, due to abnormal localization of P-gp, resulting in a high blood tacrolimus concentration. In an intestinal $\mathrm{I} / \mathrm{R}$ condition, the duration of ischemia is variable. The results of this study suggest that ROS multimodally regulate P-gp expression depending on its amount. It is important to concentrate on the amount of generated ROS after intestinal $\mathrm{I} / \mathrm{R}$ for understanding the pattern of $\mathrm{P}-\mathrm{gp}$ expression.

\section{REFERENCES}

1. Murray, HW, Cohn ZA. Macrophage oxygen-dependent antimicrobial activity. III. Enhanced oxidative metabolism as an expression of macrophage activation. J Exp Med, 1980; 152:1569-1609.

2. Varela D, Simon F, Riveros A, Jørgensen F, Stutzin A. NAD(P)H oxidase-derived $\mathrm{H}(2) \mathrm{O}(2)$ signals chloride channel activation in cell volume regulation and cell proliferation. J Biol Chem, 2004; 279:13301-13304.

3. Rojkind M, Domínguez-Rosales JA, Nieto N, Greenwel P. Role of hydrogen peroxide and oxidative stress in healing responses. Cell Mol Life Sci, 2002; 59:1872-1891.

4. Granger DN, Korthuis RJ. Physiologic mechanisms of postischemic tissue injury. Annu Rev Physiol, 1995; 57:311-332.

5. Parks DA, Bulkley GB, Granger DN, Hamilton SR, McCord JM. Ischemic injury in the cat small intestine: role of superoxide radicals. Gastroenterology, 1982; 82:9-15.

6. Saugstad OD. Mechanisms of tissue injury by oxygen radicals: implications for neonatal disease. Acta Paediatr, 1996; 85:1-4.

7. Omae T, Goto M, Shimomura M, Masuda S, Ito K, Okuda $\mathrm{M}$, Inui $\mathrm{K}$. Transient up-regulation of
P-glycoprotein reduces tacrolimus absorption after ischemia-reperfusion injury in rat ileum. Biochem Pharmacol, 2005; 69:561-568.

8. Ogura J, Kobayashi M, Itagaki S, Hirano T, Iseki K. Alteration of Mrp2 and P-gp expression, including expression in remote organs, after intestinal ischemia-reperfusion. Life Sci, 2008; 82:1242-1248.

9. Tomita M, Takizawa Y, Kishimoto H, Hayashi M. Assessment of ileal epithelial P-glycoprotein dysfunction induced by ischemia/reperfusion using in vivo animal model. Drug Metab Pharmacokinet, 2008; 23:356-363.

10. Tomita M, Takizawa $\mathrm{Y}$, Kishimoto H, Hayashi M. Effect of intestinal ischaemia/reperfusion on P-glycoprotein-mediated ileal excretion of rhodamine 123 in the rat. J Pharm Pharmacol, 2009; 61:1319-1324.

11. Ogura J, Maruyama H, Kobayashi M, Itagaki S, Iseki $\mathrm{K}$. Pharmacokinetics of oral and intravenous administration of digoxin after intestinal ischemia-reperfusion. Biol Pharm Bull, 2010; 33:922-925.

12. Boros $\mathrm{M}$, Takaichi $\mathrm{S}$, Hatanaka K. Ischemic time-dependent microvascular changes and reperfusion injury in the rat small intestine. J Surg Res, 1995; 59:311-320.

13. Ogura J, Kuwayama K, Takaya A, Terada Y, Tsujimoto T, Koizumi T, Maruyama H, Fujikawa A, Takahashi N, Kobayashi M, Itagaki S, Hirano T, Yamaguchi H, Iseki $\mathrm{K}$. Intestinal ischemia-reperfusion increases efflux for uric acid via paracellular route in the intestine, but decreases that via transcellular route mediated by BCRP. J Pharm Pharm Sci, 2012; 15:295-304.

14. Lowry OH, Rosebrough NJ, Farr AL, Randall RJ. Protein measurement with the Folin phenol reagent. J Biol Chem, 1951; 193:265-275.

15. Ogura J, Fujikawa A, Maruyama H, Kobayashi M, Itagaki S, Iseki K. Alteration of P-gp expression after intestinal ischemia-reperfusion following 16-h fasting in rats. Yakugaku Zasshi, 2011; 131:453-462.

16. Yamaguchi $H$, Yano I, Saito $H$, Inui $K$. Pharmacokinetic role of P-glycoprotein in oral bioavailability and intestinal secretion of grepafloxacin in vivo. J Pharmacol Exp Ther, 2002; 300:1063-1069.

17. Khanna A, Rossman JE, Fung HL, Caty MG. Intestinal and hemodynamic impairment following mesenteric ischemia/reperfusion. J Surg Res, 2001; 99: 114-119.

18. Niki E. Lipid peroxidation: physiological levels and dual biological effects. Free Radic Biol Med, 2009; 47:469-484. 
19. Nagira M, Tomita M, Mizuno S, Kumata M, Ayabe T, Hayashi M. Ischemia/reperfusion injury in the monolayers of human intestinal epithelial cell line caco-2 and its recovery by antioxidants. Drug Metab Pharmacokinet, 2006; 21:230-237.

20. Noda T, Iwakiri R, Fujimoto K, Matsuo S, Aw TY. Programmed cell death induced by ischemia-reperfusion in rat intestinal mucosa. Am $\mathrm{J}$ Physiol, 1998; 274:G270-G276.

21. Ikeda H, Suzuki Y, Suzuki M, Koike M, Tamura J, Tong J, Nomura M, Itoh G. Apoptosis is a major mode of cell death caused by ischaemia and ischaemia/reperfusion injury to the rat intestinal epithelium. Gut, 1998; 42:530-537.

22. Masuko T, Funayama Y, Naito H, Fukushima K, Shibata C, Takahashi K, Ogawa H, Ueno T, Hashimoto A, Miyazawa T, Nakagawa K, Matsuno S, Sasaki I. Measurement of phosphatidylcholine hydroperoxide in mild ischemia-reperfusion injury in rat intestine. Tohoku J Exp Med, 2002; 198:223-232.

23. Takizawa $\mathrm{Y}$, Kishimoto $\mathrm{H}$, Kitazato $\mathrm{T}$, Tomita $\mathrm{M}$, Hayashi M. Changes in the localization of ileal P-glycoprotein induced by intestinal ischemia/reperfusion. Biol Pharm Bull, 2011; 34:408-414.

24. Masuda S, Uemoto S, Goto M, Fujimoto Y, Tanaka K, Inui $\mathrm{K}$. Tacrolimus therapy according to mucosal MDR1 levels in small-bowel transplant recipients. Clin Pharmacol Ther, 2004; 75:352-361.
25. Shimomura M, Masuda S, Saito H, Sakamoto S, Uemoto S, Tanaka K, Inui K. Roles of the jejunum and ileum in the first-pass effect as absorptive barriers for orally administered tacrolimus. J Surg Res, 2002; 103:215-222.

26. Hayashi M, Tomita M. Transcellular and paracellular contribution to transport processes in the colorectal route. Adv Drug Deliv Rev, 1997; 28:191-204.

27. Hayashi M, Tomita M. Mechanistic analysis for drug permeation through intestinal membrane. Drug Metab Pharmacokinet, 2007; 22:67-77.

28. Takizawa Y, Kishimoto H, Kitazato T, Tomita M, Hayashi M. Changes in protein and mRNA expression levels of claudin family after mucosal lesion by intestinal ischemia/reperfusion. Int J Pharm, 2012; 426:82-89.

29. Muzii L, Marana R, Marana E, Paielli FV, Meo F, Maussier ML, Sciarra M, Mancuso S. Evaluation of stress-related hormones after surgery by laparoscopy or laparotomy. J Am Assoc Gynecol Laparosc, 1996; 3:229-234.

30. Geier A, Dietrich CG, Trauner M, Gartung C. Extrahepatic cholestasis downregulates Oatp1 by TNF-alpha signalling without affecting Oatp2 and Oatp4 expression and sodium-independent bile salt uptake in rat liver. Liver Int, 2007; 27:1056-1065.

31. Venkataramanan R, Swaminathan A, Prasad T, Jain A, Zuckerman S, Warty V, McMichael J, Lever J, Burckart G, Starzl T. Clinical pharmacokinetics of tacrolimus. Clin Pharmacokinet, 1995; 29:404-430. 